\title{
Mechanical Properties of a Hydrophilic Acrylic Polymer
}

\author{
W. J. O'BRIEN, J. HERMANN, AND T. H. SHEPHERD, School \\ of Dentistry, University of Michigan, Ann Arbor, Michigan 48104
}

\begin{abstract}
Summary
Acrylic polymers with hydrophilic groups (i.e., ethyl hydroxyl) may be prepared that convert to a soft elastic gel by absorbing water. Such a polymer has been applied to dentistry for use as an elastic lining material for dentures. A commereial product, Hydron, was used in this study. The linear expansion of this material after $520 \mathrm{hr}$ of water immersion was found to be $20.4 \%$. Hardness was found to decrease from $15.7 \mathrm{KHN}$ for the dry polymer to $1.5 \mathrm{KHN}$ at $19 \%$ absorbed water content. The swelling pressure was measured and found to reach a maximum value of $157 \mathrm{psi}$ after $204 \mathrm{hr}$ of water immersion. The Young's modulus was found to decrease from a value of 295,300 psi to 290 psi with $19 \%$ absorbed water content. Values were determined on intermediate water contents for the properties studied.
\end{abstract}

Recently, acrylic polymers have been developed that absorb water to form soft rubbery materials. These materials have hydroxy groups replacing methyl groups producing hydrophilic properties. The general formulae of methyl methacrylate and the hydroxy substituted acrylate are:

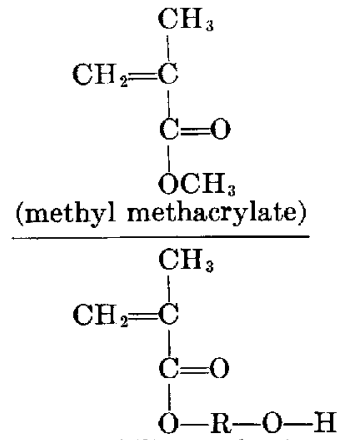

(hydrophilic acrylate)

15

(C) 1972 by John Wiley \& Sons, Inc. 
Because the hydrophilic acrylates absorb water, they are permeable to metabolites and are not as mechanically irritable as the hard solids within the body. They are finding extensive application as alloplastic and prosthetic materials. Wichterle and Lim $^{1}$ first proposed the use of hydrophilic gels for biological use in 1960 . Since then, several studies have been reported involving application as surgical implants. The animal studies indicate non-irritability, resistance to degradation, and the adherence to tissue. ${ }^{2-4}$ Other applications include use as a vehicle for the slow release of drugs within the body ${ }^{5}$ and for contact lenses. ${ }^{6}$

In the area of dentistry, these materials have been introduced as soft lining materials for dentures. The hydrophilic soft lining material is applied as a polymer-monomer dough to the tissue-bearing surface of the denture. Upon polymerization, the lining is hard and brittle. After contouring, the denture is placed in water, which converts the liner to a soft gel state. The absorbed water acts as the plasticizer in this case. Clinical studies have been reported on this application. ${ }^{7,8}$ However, information on the mechanical properties of these materials have not been reported. It is the purpose of this investigation to determine some of the basic mechanical properties of a hydrophilic polymer gel in the dry and gel states.

\section{Materials and Methods}

The material used for this study was Hydron, ${ }^{*}$ a hydroxy methacrylate that is available as a powder (polymer) and liquid (monomer) combination. A polymer-monomer ratio of $1: 1$ was used.

\section{Linear Expansion}

A rod specimen, $8 \mathrm{~cm}$ long with a diameter of $1.2 \mathrm{~cm}$, was used. The rod was placed in a glass tube of larger diameter and submerged in distilled water at $25^{\circ} \mathrm{C}$. Linear expansion was measured by means of a cathetometer at regular time intervals.

\section{Indentation Hardness}

Disk specimens, $3 \mathrm{~cm}$ diameter and lengths of $2.0 \mathrm{~cm}$, were used. A weighed quantity of distilled water was added to the monomer

*Hydron Laboratories, New Brunswick, New Jersey. 
liquid before mixing with the polymer. The Knoop Hardness Number was determined on each specimen $1 \mathrm{hr}$ after mixing. Ten replicates were run for each water content.

\section{Swelling Pressure}

Two methods of studying the pressure developed during swelling were used. In the first, the polymer-monomer mixture was poured into a 3.4-cm-long stainless steel tube of $2.9 \mathrm{~cm}$ diameter. After the material polymerized, the ends were leveled and 44 holes of $2 \mathrm{~mm}$ diameter were drilled into the tube as shown in Fig. 1. After placing in a beaker of water, the swelling force was measured by means of a compression testing machine.

The second experiment involved the swelling of immersed disks $2.9 \mathrm{~cm}$ in diameter and $0.6 \mathrm{~cm}$ long. These samples were placed between glass plates and immersed in distilled water. Again, the testing machine with a compression cell was used to measure the swelling pressure. The arrangement is shown in Fig. 2.

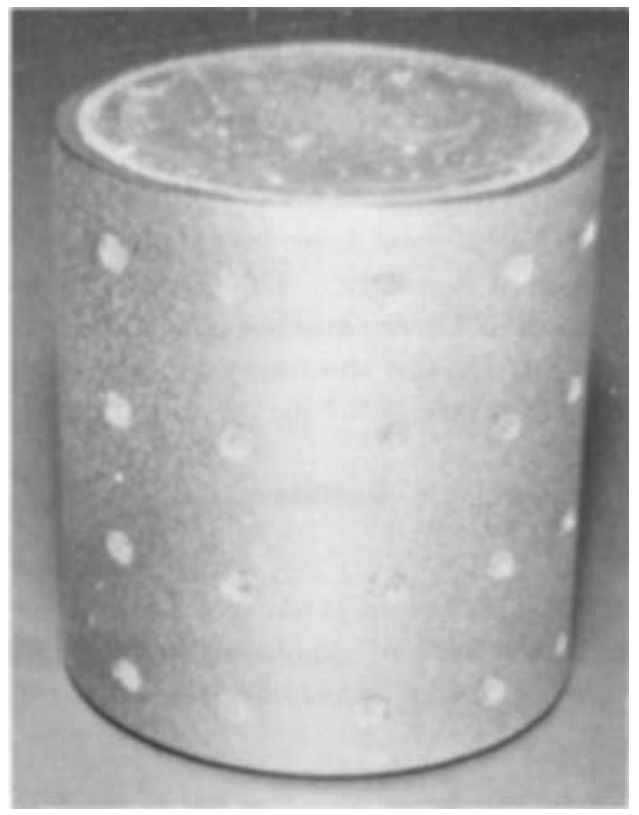

Fig. 1. Sample in perforated tube for swelling processure measurements. 


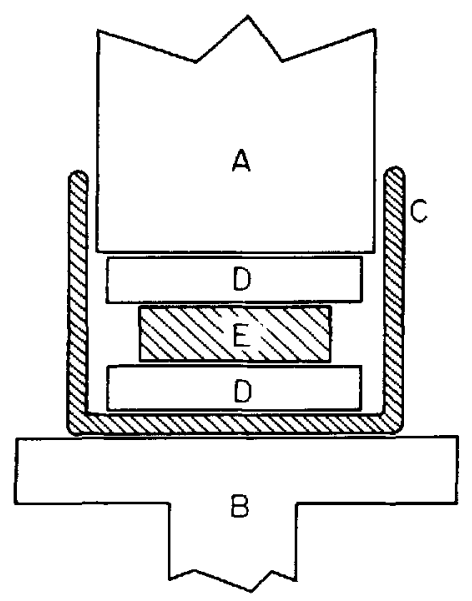

Fig. 2. Swelling pressure arrangement. (a) Crosshead used to measure compression; (b) base plate of compression cell; (c) water chamber; (d) plane glass plates; (e) disk specimen of resin.

\section{Static Tensile Properties}

The effects of water content on the tensile properties of the polymer were determined on test specimens $1.5 \mathrm{in}$. long and $0.25 \mathrm{in}$. in diameter. After determining the weight of each dry specimen, they were immersed in water for different time periods. After removal from the water, the specimens were kept for 2 days in closed flasks to allow for the diffusion of the water. Then the tensile rods were again weighed and the per cent water absorbed calculated. A stress-strain diagram was obtained for the specimens of several water contents using a crosshead strain rate of $0.1 \mathrm{in}$. per minute.

\section{Results}

\section{Linear Expansion}

The expansion per unit length is plotted in Fig. 3 as a function of time. A change in the rate of expansion was apparent between 4 and 6 days. After $520 \mathrm{hr}$ of immersion, the expansion was $20.4 \%$.

\section{Indentation Hardness}

The mean Knoop Hardness Number for the polymer specimens containing water are plotted in Fig. 4. The hardness decreases as the 


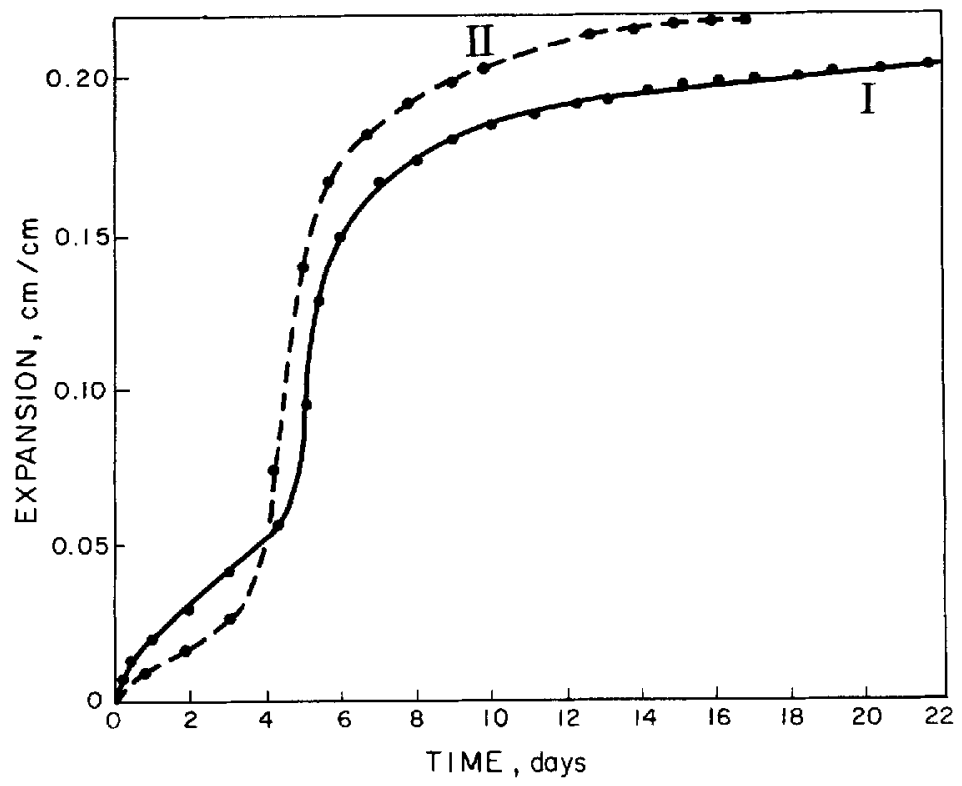

Fig. 3. Expansion of a rod of acrylic gel immersed in water.

Duplicate specimens I and II.

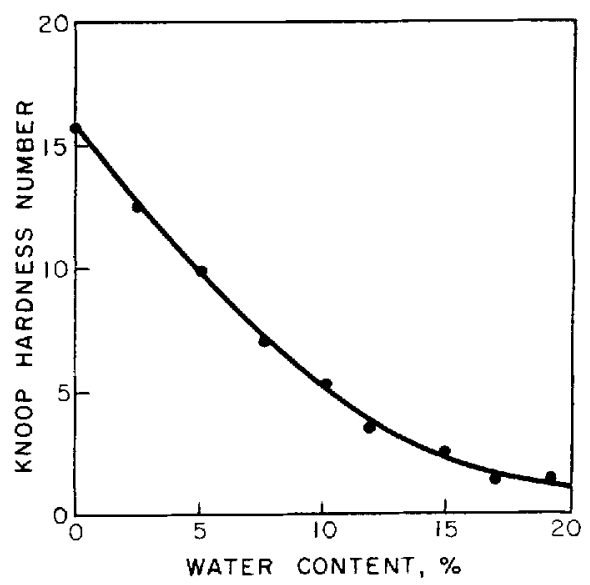

Fig. 4. Change in Knoop Hardness Number (KHN) with increased water content of acrylic gel. 
water content increased, indicating the conversion from a hard glassy resin to a soft rubbery gel. The KHN value of 15.7 for the dry polymer is close to the value of 16 reported for poly(methyl methacrylate). ${ }^{9}$

\section{Swelling Pressure}

The calculated pressure produced by the swelling polymer within the metal tube is plotted as a function of time of immersion in Fig. 5 . A maximum pressure of 157 psi was reached after $204 \mathrm{hr}$. This pressure is related to the extrusion pressure since the polymer extruded through the holes of the metal tube as shown in Fig. 6.

In the swelling pressure measurement in which disks were held between glass plates gave the results shown in Fig. 7. The maximum pressure was $15 \tilde{5}$ psi after 23 days. This result is close to the 157 psi found using the metal tube.

\section{Static Tensile Properties}

Figure 8 shows the tensile stress-strain curves for the several water contents. The mechanical properties obtained from these tests are given in Table I. The moduli of elasticity values were calculated using the initial slope of the stress-strain curves. As ex-

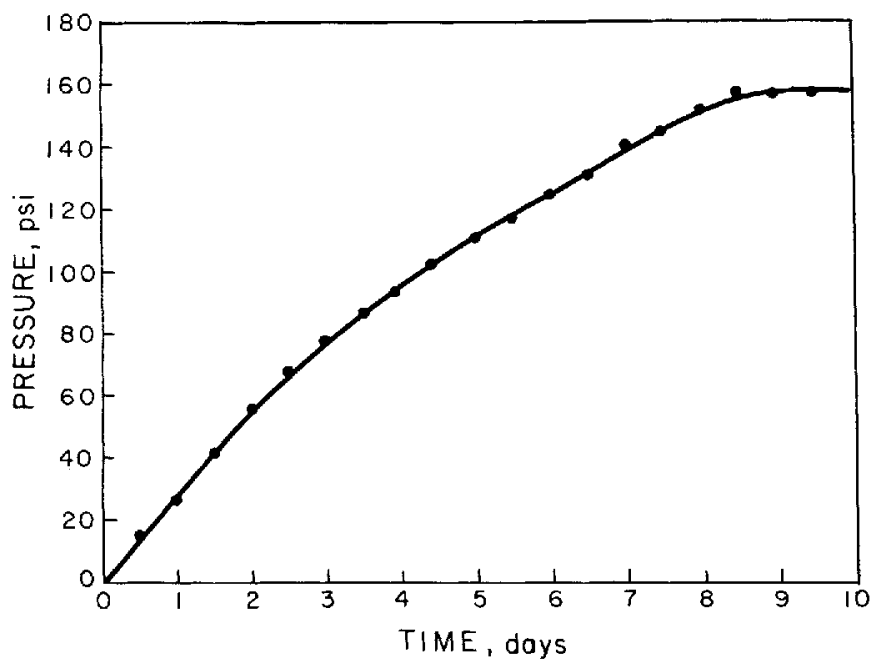

Fig. 5. Swelling pressure of gel within perforated tube. 


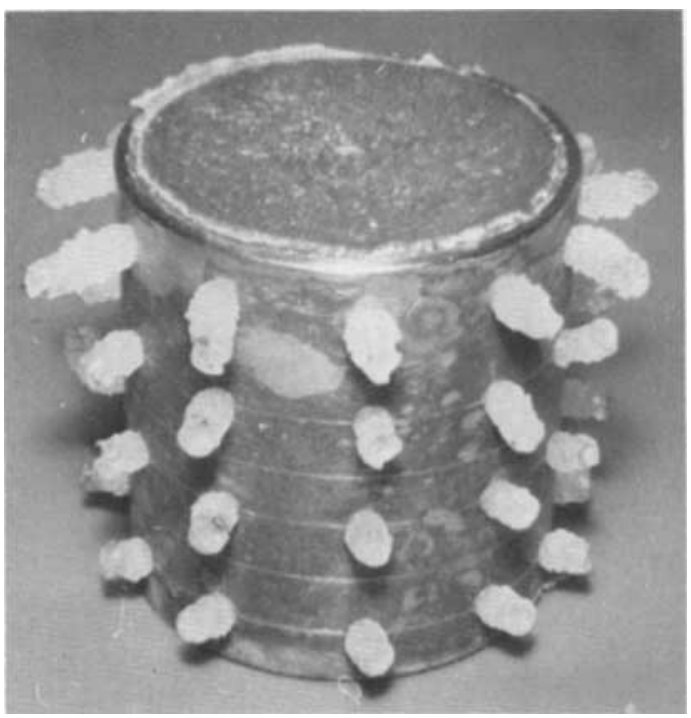

Fig. 6. Extrusion of acrylic gel during immersion in water.

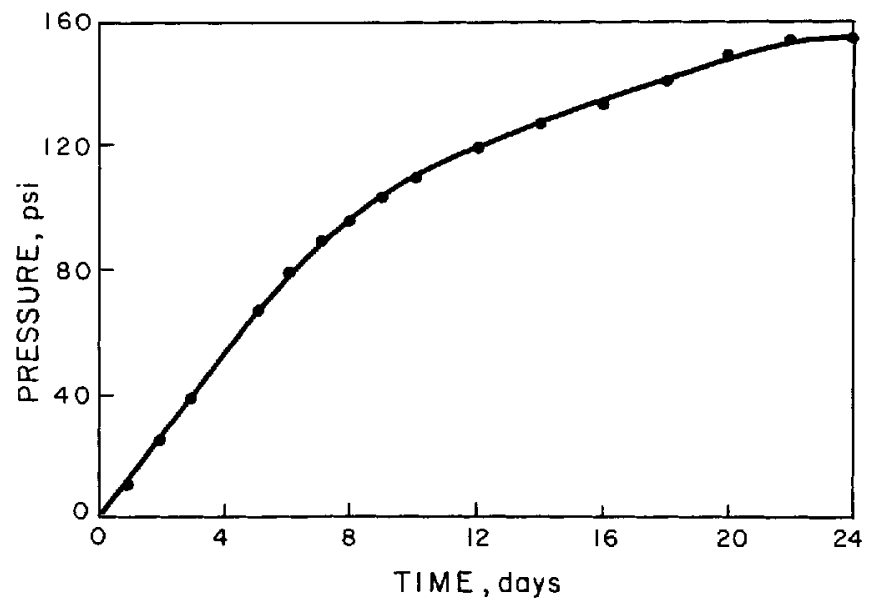

Fig. 7. Swelling pressure of acrylic gel disk specimens between glass plates. 
O'BRIEN ET AL.

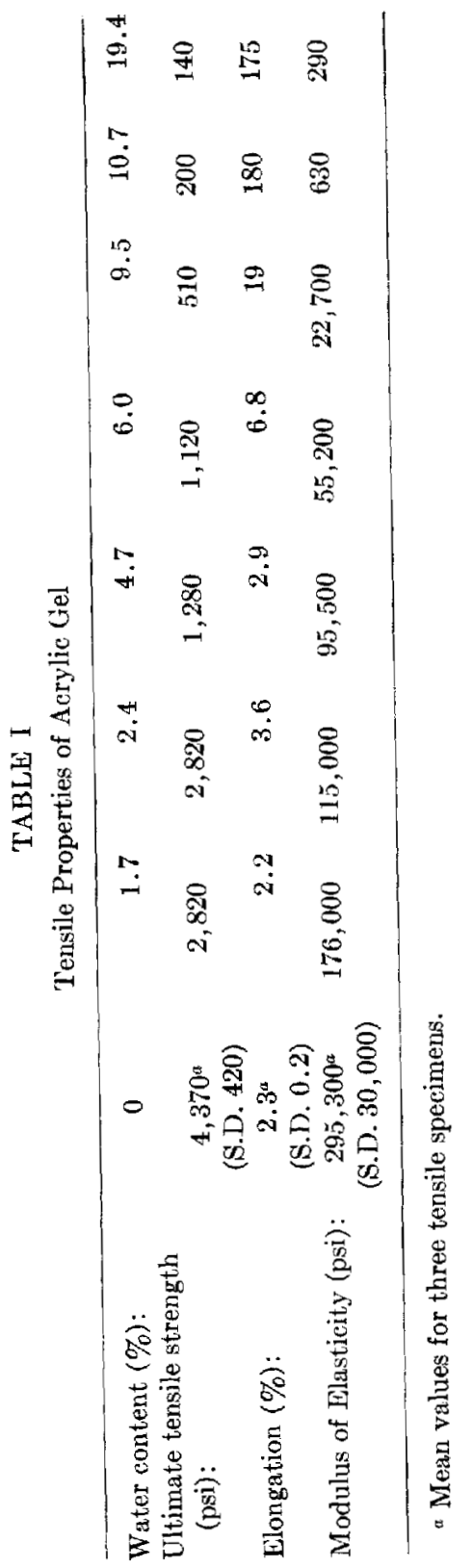




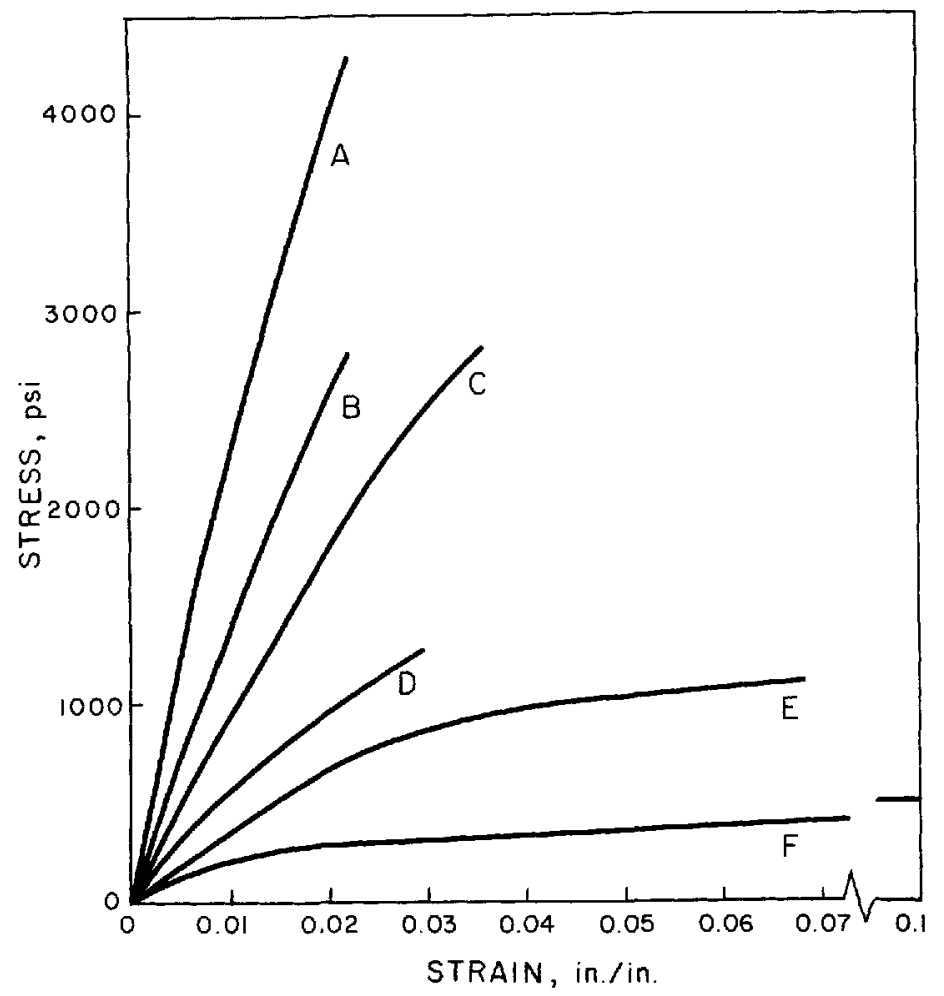

Fig. 8. Tensile stress-strain curves for aerylic gel material corresponding to the following water contents: (a) 0 ; (b) $1.7 \%$; (2) $2.4 \%$ (d) $4.7 \%$; (e) $6.0 \%$; (f) $9.5 \%$; (g) $10.7 \%$; and (h) $19.4 \%$.

pected, the tensile strength and modulus of elasticity values decreased rapidly with increasing water content. The ductility increased from a value of $2.3 \%$ for the dry polymer to $175 \%$ for a $19.4 \%$ water content.

The author wishes to acknowledge the assistance of Joachim Hermann in conducting the laboratory measurements and to Dr. Thomas H. Shepherd for his cooperation.

\section{References}

1. O. Wichterle and D. Lim, Nature, 185, 117 (1960).

2. M. Barvic, K. Kliment, and M. Zavadel, J. Biomed. Mater. Res., 1, 313 (1967). 
3. S. Kocvara et al., J. Biomed. Mater. Res., 1, 325 (1967).

4. M. Barvic, Acta Univ. Car. Medica, 8, 707 (1962).

5. J. N. LaGuerre et al., J. Amer. Med. Assoc., 206, 1190 (1968).

6. D. G. Ewell, Opt. Weekly, 56, 6 (1965).

7. K. Kliment et al., J. Biomed. Mater. Res., 2, 473 (1968).

8. B. Battersby, D. Gehl and W. J. O'Brien, J. Pros. Dent., 20, 498 (1968).

9. F. Peyton et al, "Restorative Dental Materials," Mosby Co., St. Louis, p. 504 (1968).

Received October 29, 1970 